\title{
NMR detected metabolites in complex natural fluids. Quinic acid in apple juice
}

\author{
Gabriela Liliana AILIESEI, ${ }^{1}$ Mihaela CIOBANU,${ }^{1}$ Mihaela BALAN,${ }^{1}$ Cristina STAVARACHE,${ }^{2}$ Lucica \\ BARBES ${ }^{3}$ Alina NICOLESCU, ${ }^{*}, 1,2$ and Calin DELEANU ${ }^{1,2}$ \\ 1 “Petru Poni” Institute of Macromolecular Chemistry, Romanian Academy, Group of Biospectroscopy, Aleea \\ Grigore Ghica 41-A, RO-700487 Iasi, Romania \\ 2 “Costin D. Nenitescu” Centre of Organic Chemistry, Romanian Academy, Group of Biospectroscopy, Spl. \\ Independentei 202-B, RO-060023 Bucharest, Romania \\ 3 “Ovidius" University of Constanta, Department of Chemistry and Chemical Engineering, Bd. Mamaia 124, \\ RO-900527 Constanta, Romania
}

\begin{abstract}
Different types of 1D and 2D NMR experiments were used to completely characterize quinic acid and demonstrate its presence in complex mixtures. The identification of quinic acid in apple juice was done without any separation step. The NMR experiments presented in this study can be used to analyze other metabolites in different complex natural fluids, of vegetal or biological origin.
\end{abstract}

Keywords: Quinic acid, NMR, apples, juice, beverages.

\section{Introduction}

Nuclear Magnetic Resonance (NMR) spectroscopy is one of the most versatile tool available for characterizing complex natural mixtures, providing information on both global profile of the sample and the individual metabolites. Currently, chemometric methods are used with highthroughput analytical platforms like NMR spectroscopy or gas/liquid chromatography, mass spectrometry (GC-MS / LC-MS) to study foods for composition, quality control, such as monitoring of genetically modified crops in order to detect any unintended effects [1-4], authenticity, such as determination of geographic origin of products like olive oil [5] or honeys [6], metabolic fingerprinting [7-11], or adulteration [12-15]. Although there are many studies on NMR characterization of foods, the only high resolution NMR spectroscopy technique that is accepted as official standard method in food analysis is the SNIF-NMR (Site Specific Isotope Fractionation by NMR) method for wine authentication [16-19]. Recent developments of hardware, software and automation, allowing highthroughput, reduced experimental time and detection of compounds in small concentrations (even nanograms, if cryoprobes are used) are "promoting" the NMR techniques towards new official standard methods in food analysis and even medicine.

Our group used high resolution NMR spectroscopy to study various food samples including, edible oils [20-25], rhubarb juice [26], fruits and vegetables [27-29] and wines [30-32].

Food materials have a wide range of physical states and chemical compositions, thus requiring the use of different NMR techniques to obtain detailed characterization [33, 34]. One challenging tasks remains the identification and quantification of metabolites in the analyzed foodstuffs.

The present paper reports on different NMR experiments used to completely characterize a metabolite and demonstrate its presence in complex mixtures, such as food samples. We have chosen to exemplify the NMR experiments on quinic acid $-\mathrm{a}$ metabolite with a complicated ${ }^{1} \mathrm{H}$ NMR spectrum, and demonstrate its presence in apple juice.

\section{Experimental}

\subsection{Sample preparation}

Fresh juices were prepared in the laboratory using a garlic press. The Golden apple was pilled before being squeezed while the blackcurrants were squeezed as a whole. The obtained juices were centrifuged for 10 minutes at 7000 rotations per minute in order to remove any solid particles. $4 \mathrm{~mL}$ from each fresh juice were kept at $-20^{\circ} \mathrm{C}$ until NMR analysis. Prior to NMR analysis, the juice samples were allowed to thaw at room temperature for 20 minutes. For the NMR analysis $500 \mu \mathrm{L}$ of juice was mixed with $500 \mu \mathrm{L}$ of $5 \mathrm{mM}$ sodium 3(trimethylsilyl)-[2,2,3,3- $\left.\mathrm{d}_{4}\right]-1$-propionate (TSP) in

*Corresponding author: alina@icmpp.ro 
$\mathrm{D}_{2} \mathrm{O}(99.8 \% \mathrm{D}$, Aldrich) solution. $600 \mu \mathrm{L}$ of sample were transferred into a $5 \mathrm{~mm}$ Wilmad $507 \mathrm{NMR}$ tube and subjected to the NMR analysis.

Approximately $10 \mathrm{mg}$ of quinic acid $(98 \%$, Aldrich) was dissolved in $700 \mu \mathrm{L} \mathrm{D}_{2} \mathrm{O}$ containing TSP as internal standard. The obtained solution was transferred into the $5 \mathrm{~mm}$ Wilmad 507 NMR tube and subjected to the NMR analysis.

\subsection{NMR Measurements}

The NMR spectra were recorded on a Bruker Avance III 400 spectrometer, operating at 400.13 $\mathrm{MHz}$ for ${ }^{1} \mathrm{H}$ and $100.63 \mathrm{MHz}$ for ${ }^{13} \mathrm{C}$ nuclei. Samples were recorded with either a $5 \mathrm{~mm}$ four nuclei direct detection z-gradient probe or with a $5 \mathrm{~mm}$ multinuclear inverse detection $\mathrm{z}$-gradient probe. Unambiguous 1D NMR signal assignments for quinic acid were made based on 2D NMR homo- and heterocorrelation. H,H COSY, H,C HSQC and H,C HMBC experiments were recorded using standard pulse sequences in the version with z-gradients, as delivered by Bruker with TopSpin 2.1 PL6 spectrometer control and processing software.

The juices spectra have been recorded with the NOESY presaturation pulse sequence. The chemical shifts are reported as $\delta$ values (ppm) and referred to TSP $(0.0 \mathrm{ppm})$ as internal standard.

\section{Results and Discussions}

Fruit juices exhibit complex ${ }^{1} \mathrm{H}$ NMR spectra with hundreds of signals from different metabolites. Although there are many reports in the literature dealing with NMR characterization of fruit juices, not all the signals present in the ${ }^{1} \mathrm{H}$ NMR spectra have been assigned to specific metabolites. This complexity is caused by "natural" variations in the chemical composition of the fruits (the environmental conditions, cultivar type, meteorological conditions, degree of ripping, storage condition, etc.) and also "artificially" induced variations (manufacturing procedures, additives, packing materials, etc).

The ${ }^{1} \mathrm{H}$ NMR spectrum of a fruit juice can be rationalized in three regions, as it can be seen in Fig. 1 , the high field region between 0.5-3.1 ppm, with various signals corresponding to aliphatic metabolites such as amino acids, carboxylic acids and alcohols, the intermediate region between 3.1$6.0 \mathrm{ppm}$ dominated by signals from different sugars and the low field region between 6.0-9.0 ppm with signals corresponding to aromatic derivatives, heterocycles, organic acids and polyphenols. This spectral "fingerprint" is characteristic to different fruit juices, with some variations in signals intensities, depending on metabolites concentrations in the analyzed juice.

Quinic acid is a cyclic polyol, found in different fruits such as cranberries, apples, blackcurrants, plums, peaches, etc. It is also one of the major acids found in green and roasted coffee [35, 36]. The concentration of quinic acids in plants is variable, and this is translated in different NMR profile of the analyzed fruit juice.

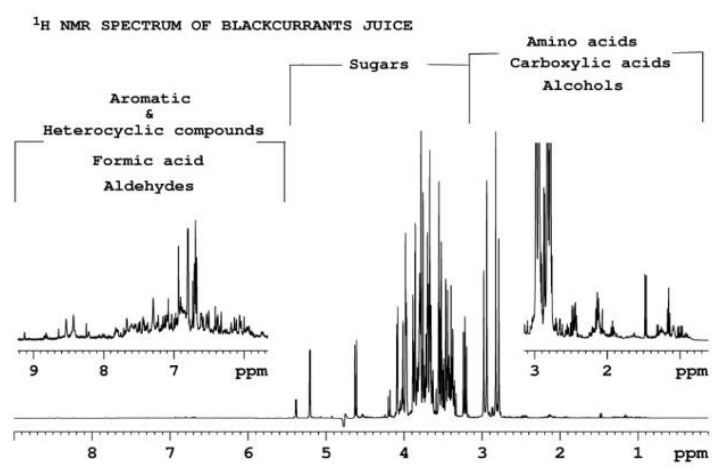

Figure 1. Main regions of ${ }^{1} \mathrm{H}$ NMR spectrum for blackcurrants juice.

In figure 2, quinic acid profile is exemplified in apple and blackcurrants juices. As it can be seen, in apple juice several signals corresponding to quinic acid are intense and can be relatively easy identified (Fig. 2A). By contrast, in the blackcurrants juice, only one less intense peak can be observed for quinic acid (Fig. 2B). This is due to the lower concentration of quinic acid in blackcurrants, as compared with apples.

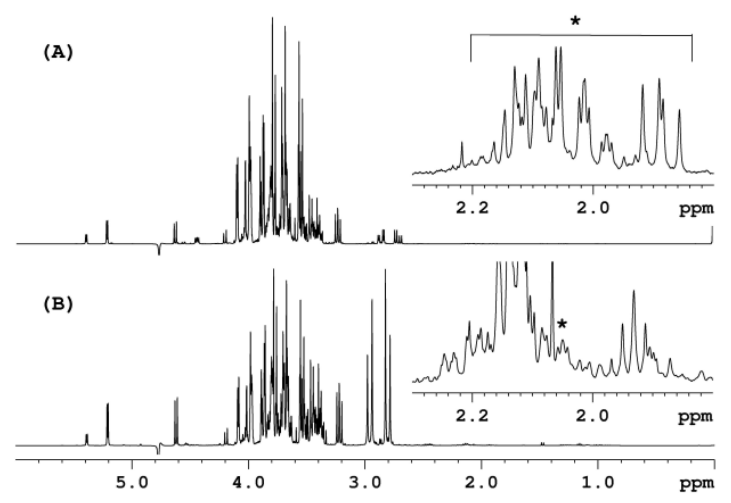

Figure 2. The ${ }^{1} \mathrm{H}$ NMR spectra for A) Golden apple and B) blackcurrants juices. The spectral windows contain only aliphatic derivatives and sugars regions. The * denotes signals characteristic to quinic acid in the two analyzed juices.

\section{Complete NMR characterization of quinic acid}

Since fruit juices are aqueous solutions, all NMR experiments have been performed in aqueous solution of quinic acid. The obtained ${ }^{1} \mathrm{H}$ NMR spectrum for quinic acid is presented in Fig. 3, with assignments of different protons signals. The signals corresponding to hydroxyl protons do not appear in the ${ }^{1} \mathrm{H}$ NMR spectrum due to the rapid exchange with deuterium from the deuterated water used as solvent. In the ${ }^{1} \mathrm{H}$ NMR spectrum of quinic acid one can identify seven different signals, with 
complicated coupling patterns. The signals can be assigned as follows: $1.94\left(1 \mathrm{H}, \mathrm{dd},{ }^{2} J_{H 2 \alpha-H 2 \beta}=13.6\right.$ $\left.\mathrm{Hz},{ }^{3} J_{H 2 \alpha-H 3}=10.8 \mathrm{~Hz}, \mathrm{H}-2 \alpha\right), 2.07\left(1 \mathrm{H}, \mathrm{ddd},{ }^{2} J_{H 6 \beta-}\right.$ ${ }_{H 6 \alpha}=14.8 \mathrm{~Hz},{ }^{3} J_{H 6 \beta-H 5}=3.4 \mathrm{~Hz},{ }^{4} J_{H 6 \beta-H 2 \beta}=2.8 \mathrm{~Hz}$,

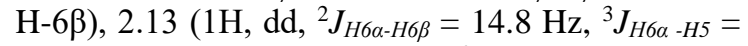
$3.2 \mathrm{~Hz}, \mathrm{H}-6 \alpha), 2.18\left(1 \mathrm{H}\right.$, ddd, ${ }^{2} J_{H 2 \beta-H 2 \alpha}=13.2 \mathrm{~Hz}$, $\left.{ }^{3} J_{H 2 \beta-H 3}=4.6 \mathrm{~Hz},{ }^{4} J_{H 2 \beta-H \sigma \beta}=2.4 \mathrm{~Hz}, \mathrm{H}-2 \beta\right), 3.57(1 \mathrm{H}$, $\left.\mathrm{dd},{ }^{3} J_{H 4-H 3}=9.2 \mathrm{~Hz},{ }^{3} J_{H 4-H 5}=3.2 \mathrm{~Hz}, \mathrm{H}-4\right), 4.05(1 \mathrm{H}$, ddd, ${ }^{3} J_{H 3-H 2 \alpha}=10.8 \mathrm{~Hz},{ }^{3} J_{H 3-H 4}=9.4 \mathrm{~Hz},{ }^{3} J_{H 3-H 2 \beta}=$ $4.4 \mathrm{~Hz}, \mathrm{H}-3), 4.18\left(1 \mathrm{H}, \mathrm{ddd},{ }^{3} J_{H 5-H 6 \alpha}={ }^{3} J_{H 5-H 6 \beta}={ }^{3} J_{H 5}\right.$ $\left.H_{4}=3.2 \mathrm{~Hz}, \mathrm{H}-5\right)$. All these assignments are based on different types of 2D NMR experiments which will be described below.
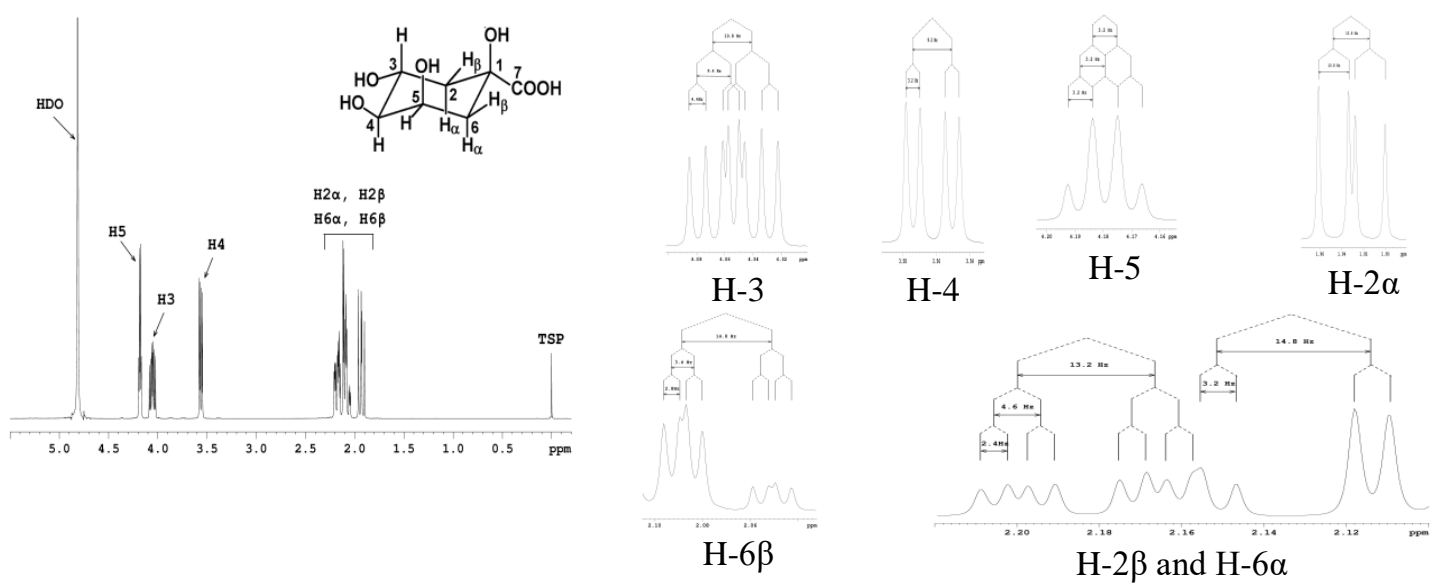

Figure 3. The ${ }^{1} \mathrm{H}$ NMR spectrum of quinic acid, recorded in $\mathrm{D}_{2} \mathrm{O}$. The shape of each signal and the coupling constant patterns are presented.

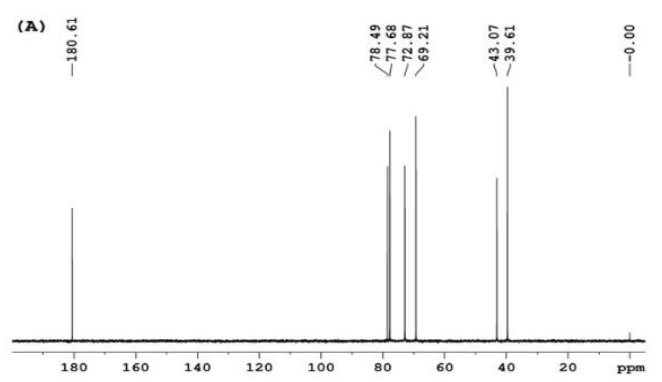

Figure 4. A) The ${ }^{13} \mathrm{C}$ NMR and B) DEPT 135 NMR spectra of pure quinic acid.
In the ${ }^{13} \mathrm{C}$ NMR spectrum of quinic acid (Fig. 4A) there are seven signals corresponding to each of the seven carbon atoms from the structure. The most deshielded signal, from $180.61 \mathrm{ppm}$, is attributed to carboxylic carbon $\mathrm{C}-7$, in the chemical shift region 65-80 ppm there are three signals corresponding to the three methyne carbon atoms $(\mathrm{C}-3, \mathrm{C}-4$ and $\mathrm{C}-5)$ together with one signal corresponding to the quaternary $\mathrm{C}-1$ carbon.

The most shielded signals are the two methylene carbons C-2 and C-6. Usually, ${ }^{13} \mathrm{C}$ NMR spectra are recorded with total elimination of the proton couplings (broad band decoupling; this helps in gaining signal intensity, thus reducing the acquisition time of the experiment, and also reduces almost completely the superposition of signals). Due to this reason, all the signals in this type of spectra are singlets, being difficult to differentiate between the types of protonated carbon atoms. To overcome this inconvenient, DEPT (Distortionless Enhancement by Polarization Transfer) experiments can be used. In the DEPT 135 spectrum presented in

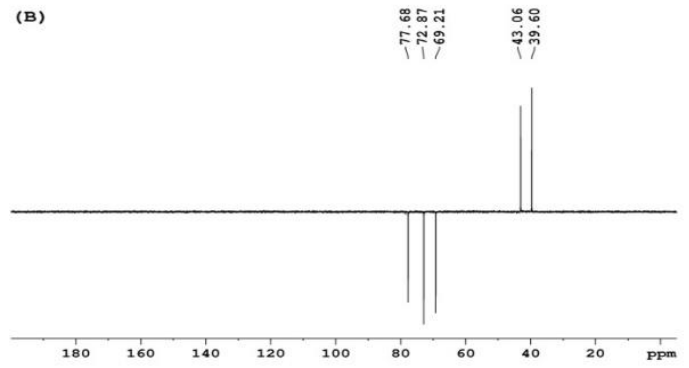

Fig. 4B, on the positive side appear signals from methylene carbons and in the negative side appear the methynes carbons. Signals from quaternary carbons do not appear in DEPT 135 spectrum. Using the information from DEPT 135 and 2D experiments, the signals from 13C NMR spectrum can be assigned as follows: 39.61 (C-6), 43.07 (C-2), 69.21 (C-3), 72.87 (C-5), 77.68 (C-4), 78.49 (C-1), $180.61(\mathrm{COOH})$.

2D NMR experiments may be performed as homo- (correlations between the same types of nuclei) and heteronuclear (correlations between two types of nuclei) experiments.

The most often used 2D homonuclear experiment is $\mathrm{H}, \mathrm{H}$ COSY (COrrelation SpectroscopY), showing correlations between the $J$-coupled protons. The $\mathrm{H}, \mathrm{H}$ COSY corresponding to quinic acid is presented in Fig. 5A. In this spectrum, one can observe the diagonal peaks - which correspond to the signals from ${ }^{1} \mathrm{H}$ NMR spectrum, and the cross peaks showing the couplings between J-coupled protons. For structure elucidation purposes, the cross peaks 
have to be identified. Some examples in the COSY spectrum of the quinic acid are the cross peaks for couplings between $\mathrm{H}-2 \alpha$ and $\mathrm{H}-3$, and couplings

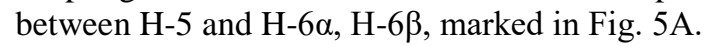

The H,C HSQC (Heteronuclear Single Quantum Correlation) spectrum corresponding to quinic acid is presented in Fig. 5B. In the 2D spectrum, six correlation peaks can be observed indicating the direct couplings of the protons with the corresponding carbons. In order to assign these peaks, lines are drawn at a right angle, from the proton spectrum to the carbon spectrum, intersecting the correlation peak. An example is presented in Fig. $5 \mathrm{~B}$, showing the direct attachment of $\mathrm{H}-4$ to $\mathrm{C}-4$. Another case is represented by the two correlation peaks which appear on the same line drawn from C2. This situation occurs because the two protons from the $\mathrm{CH}_{2}-2$ group are not chemically equivalent and resonate in the ${ }^{1} \mathrm{H}$ NMR spectrum at different chemical shifts, at $1.94 \mathrm{ppm}(\mathrm{H}-2 \alpha)$ and $2.18 \mathrm{ppm}$ $(\mathrm{H}-2 \beta)$. Quaternary carbons do not give correlation peaks in this spectrum.
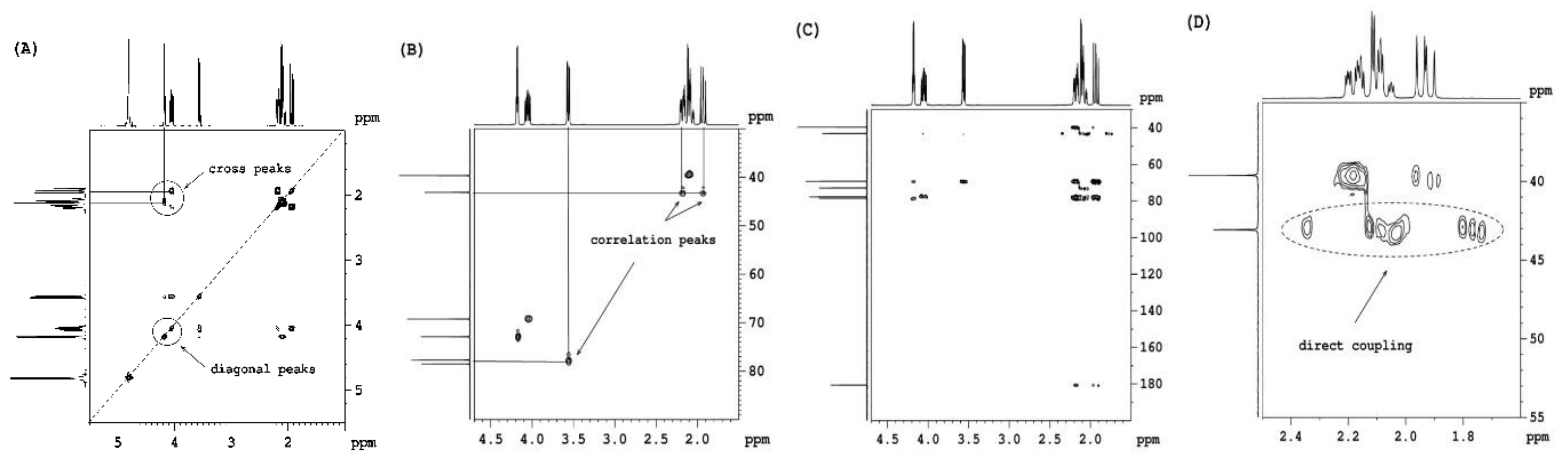

Figure 5. 2D NMR spectra of pure quinic acid, used for metabolite signal assignments: A) H,H COSY, B) H,C HSQC, C) H,C HMBC - entire spectral width, D) H,C HMBC - aliphatic region.

The H,C HMBC (Heteronuclear Multiple Bond Correlation) spectrum corresponding to quinic acid is presented in Fig. 5C and 5D. In this spectrum more correlation peaks can be observed, as compared with $\mathrm{H}, \mathrm{C}$ HSQC spectrum, since these peaks are due to multiple bond correlations between protons and carbons. The spectrum is interpreted in the same way as the HSQC spectrum. An important difference is that in HMBC spectrum correlation peak between protons and quaternary carbons can be observed. Such examples are the correlation peaks observed in Fig. 5C for $\mathrm{COOH}$ (at $180.61 \mathrm{ppm}$ ) with $\mathrm{H}-2 \alpha$ (at $1.94 \mathrm{ppm}$ ) and $\mathrm{H}-2 \beta$ (at $2.18 \mathrm{ppm}$ ). In the detailed HMBC spectrum present in Fig. 5D, a different type of correlation peaks are highlighted. These are the direct $\mathrm{H}-\mathrm{C}$ coupling, which in the HMBC spectrum appear as a pair of two peaks situated on the position of the ${ }^{13} \mathrm{C}$ satellites from the ${ }^{1} \mathrm{H}$ NMR spectrum.

The three types of 2D NMR experiments presented above were used to make the full ${ }^{1} \mathrm{H}$ and ${ }^{13} \mathrm{C}$ signals assignments.

\section{Detection of quinic acid in the apple juice}

We exemplify below the use of NMR techniques for the identification of quinic acid in the apple juice, with minimum preparation and no separation of the juice sample. Apple juice is a complex mixture, containing vitamins, minerals, sugars and many specific metabolites like different aminoacids, carboxylic acids, alcohols or polyphenols. It is also one of the fruit juices used as illegal mixture with other more expensive juices, thus its complete characterization is valuable for the food industry.

As all juices, either freshly squeezed or industrially processed, apple juice contains water as the major component. Thus, the normal ${ }^{1} \mathrm{H}$ NMR spectrum (not shown here) will display an intense signal corresponding to the water protons, while the signals for the other organic components will be very small and most of them overlapped by the water signal. To overcome this inconvenient, water signal is usually suppressed, using different pulse sequences. The ${ }^{1} \mathrm{H}$ NMR spectrum of apple juice, recorded with the suppression of the water signal, is presented in Fig. 6A. Without the dominant water signal, many other signals corresponding to the organic components of the juice become visible. With such a large number of resonances, a complete assignment is difficult to be done. However, there are some regions which are less crowded, where the signals are differentiated and can be assigned to the corresponding compounds.

If one compares the 1D proton spectrum of the apple juice (Fig. 6A) with the one corresponding to quinic acid (Fig. 6B), signals belonging to the quinic acid resonating in the region 1.80-2.20 ppm appear in both spectra, being thus suitable as assignment candidates. The number of the signals, their multiplicity and the chemical shifts are similar in both spectra. On the other hand, signals resonating in the region 3.57-4.19 ppm, corresponding to quinic acid $\mathrm{H}-3, \mathrm{H}-4$ and $\mathrm{H}-5$ protons, are not visible in the juice spectrum, being overlapped by the more 
intense sugars signals, and making the quinic acid assignment uncertain in this later region.

A)

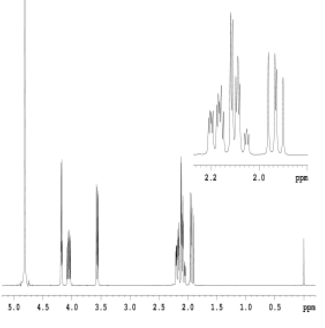

Figure 6. The ${ }^{1} \mathrm{H}$ NMR spectra of A) fresh Golden apple juice and $\mathrm{B}$ ) quinic acid in $\mathrm{D}_{2} \mathrm{O}$.

To confirm the presence of quinic acid in this complex mixture, 2D NMR experiments can be used. Thus, Figure 7 presents the assignment of the three overlapped quinic acid signals corresponding to $\mathrm{H}-3, \mathrm{H}-4$ and $\mathrm{H}-5$ protons via cross peaks from 2D $\mathrm{H}, \mathrm{H}$ COSY spectrum of the apple juice. Similarly with the proton experiment, the COSY experiment was performed with simultaneous water suppression. As mentioned above, the region 1.80-
$2.20 \mathrm{ppm}$ is not so crowded and the peaks corresponding to $\mathrm{CH}_{2}-2$ and $\mathrm{CH}_{2}-6$ protons from quinic acid are easily identified. In figure $7 \mathrm{~B}$, the cross peaks corresponding to the couplings between $H-2 \alpha$ and $H-2 \beta$ and $H-6 \alpha$ and $H-6 \beta$ are clearly visible. Using the spread of resonances in the extra dimension, H-3 and H-5 are identified, under the sugar signals, through their coupling with $\mathrm{H}-2$ and H-6 (Fig. 7C). The signal of H-4 is identified through the couplings with H-3 (Fig. 7D).

Using the same approach other metabolites present in the apple juice can be identified. The region 3.1-6.0 ppm is dominated by different sugars, some characteristic signals being at $4.10 \mathrm{ppm}$ for fructose, $5.19 \mathrm{ppm}$ for galactose, $5.23 \mathrm{ppm}$ for glucose and $5.40 \mathrm{ppm}$ for sucrose. A major metabolite present in apples is malic acid, with characteristic signals in the interval $2.68-2.88 \mathrm{ppm}$. Other metabolites are citramalic acid, having the characteristic signal at $1.42 \mathrm{ppm}$ or alanine, with the corresponding signal at $1.47 \mathrm{ppm}$.
A)

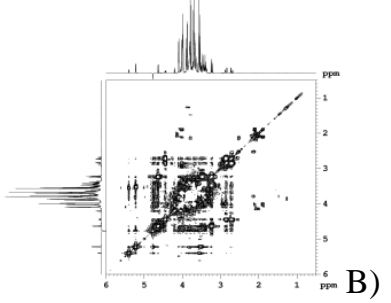

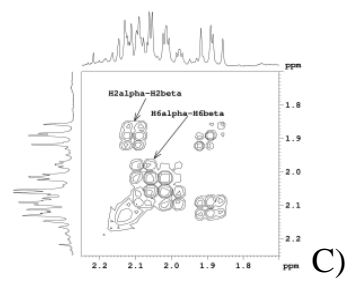
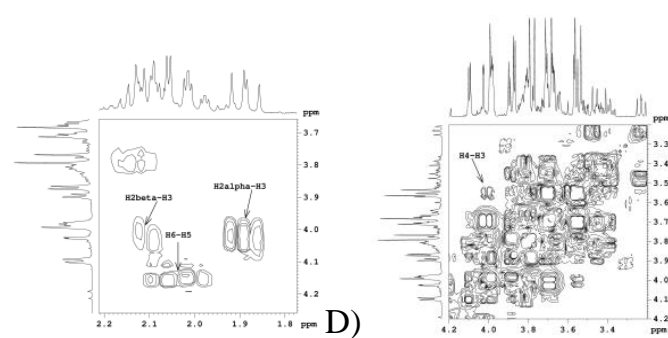

Figure 7. The H,H COSY spectrum of apple juice, recorded with water suppression: A) the entire spectral window; B) detailed region showing the signals characteristic to $\mathrm{CH}_{2}-2$ and $\mathrm{CH}_{2}-6$ protons; C) detailed region showing the signals characteristic to $\mathrm{CH}_{2}-2, \mathrm{CH}_{2}-6, \mathrm{H}-3$ and $\mathrm{H}-5$ protons; D) detailed region showing the signals characteristic to $\mathrm{H}-3$ and $\mathrm{H}-4$ protons.

\section{Conclusions}

Different types of 1D and 2D NMR experiments have been used for the detailed NMR characterization of quinic acid. The identification of quinic acid in apple juice without any separation step was described. The NMR experiments presented in this study can be used to analyze other metabolites in different complex natural fluids, of vegetal or biological origin.

\section{Acknowledgments}

This work was supported by a grant of the Romanian National Authority for Scientific Research, CNCS-UEFISCDI, project number PN-IIPT-PCCA-2013-4-0791.

\section{References}

[1]. H. A. Kuiper, G. A. Kleter, H. P. Noteborn, and E. J. Kok, Plant J. 49, 580 (2001).

[2]. L. W. Sumner, P. Mendes, and R. A. Dixon, Phytochemistry 62, 817 (2003).
[3]. R. N. Tretheway, Curr. Opin. Plant Biol. 7, 196 (2004).

[4]. G. Le Gall, I. J. Colquhoun, A. L. Davis, and G. J. Collins, M. E. Verhoeyen, J. Agric. Food Chem. 51, 2447 (2003).

[5]. G. Vlahov, P. Del Re, and N. Simone, J. Agric. Food Chem. 51, 5612 (2003).

[6]. R. Consonni, and L. R. Cagliani, J. Agric. Food Chem. 56, 6873 (2008).

[7]. P.S. Belton, I. Delgadillo, A.M. Gil, P. Roma, F. Casuscelli, I.J. Colquhoun, M.J. Dennis and M. Spraul, Magn. Reson. Chem. 35, S52 (1997).

[8]. P.S. Belton, I.J. Colquhoun, E.K. Kemsley, I. Delgadillo, P. Roma, M.J. Dennis, M. Sharman, E. Holmes, J.K. Nicholson and M. Spraul, Food Chem. 61, 207 (1998).

[9]. M. Cuny, G.Le Gall, I.J. Colquhoun, M. Lees and D.N. Rutledge, Anal. Chim. Acta. 597, 203 (2007).

[10]. M. Cuny, E. Vigneau, G.Le Gall, I. Colquhoun, M. Lees and D.N. Rutledge, Anal. Bioanal. Chem. 390, 419 (2008). 
[11]. K. Ali, F. Maltese, A. M. Fortes, M. S. Pais, R. Verpoorte and Y. H. Choi, Anal. Chim. Acta 703, 179 (2011).

[12]. J.T.W.E. Vogels, L. Terwel, A.C. Tas, F. van den Berg, F. Dukel and J. van der Greef, J. Agric. Food Chem. 44, 175 (1996).

[13]. G. Le Gall, M. Puaud and I.J. Colquhoun, J. Agric. Food Chem. 49, 580 (2001).

[14]. M. Spraul, B. Schütz, P. Rinke, S. Koswig, E. Humpfer, H. Schäfer, M. Mörtter, F. Fang, U. C. Marx and A. Minoja, Nutrients 1, 148 (2009).

[15]. M. Spraul, B. Schütz, E. Humpfer, M. Mörtter, H. Schäfer, S. Koswig and P. Rinke, Magn. Reson. Chem. 47, S130 (2009).

[16]. G. E. Martin, J. E. Noakes, F. C. Alfonso, and D. M. Figert, J. Assoc. Off. Anal. Chem. 64, 1142 (1981).

[17]. "OIV 1990. Recueil des méthodes internationales d'analyse des vins et des moûts", Office International de la Vigne et du Vin, Paris, 107 (1990).

[18]. EC Regulation 2676/90 (Sept 17, 1990). "Detecting enrichment of grape musts, concentrated grape musts, rectified concentrated grape musts and wines by application of nuclear magnetic resonance of deuterium (SNIF-NMR/RMN-FINS)", Offic. J. Eur. Communities 64, No L272 (1990).

[19]. C. Guillou, E. Jamin, G. E. Martin, F. Reniero, R. Wittkowski, and R.Wood, Bull.O.I.V. 74, 26 (2001).

[20]. C. Deleanu, C. Enache, M. T. Caproiu, G. Cornilescu and A. Hirtopeanu, "Methyl Esters of Fatty Acids. Model Compounds for Assignment of Signals in High Resolution NMR Spectra of Edible Oils", in: "Contributions to Spectroscopic Based Food Research from Central and Eastern European Participants", (Ed. C.N.G. Scotter), Commission of the European Communities, Brussels, 1994, pp. 53-64.

[21]. C. Deleanu, M. T. Caproiu, G. Cornilescu, C. Enache and A. Hirtopeanu, "Applications of High Field High Resolution Nuclear Magnetic Resonance Spectroscopy to the Authentication of Edible Oils", in: "Food Authentication by Spectroscopic Techniques", (Eds. M. Lees and C.N.G. Scotter), Commission of the European Communities, Brussels, 1994, pp. 29-38.
[22]. C. Deleanu, C. Enache, M. T. Caproiu, G. Cornilescu and A. Hirtopeanu, Rev. Chim. (Bucharest) 45, 1046 (1994).

[23]. A. Ciocarlan, V. Abramov, A. Dascaliuc, E. Efremov, M. Deleanu, M.-C. Buzas and C. Deleanu, Anal. St. Univ. Stat Moldova Ser. Chim.-Biol., 503 (2004).

[24]. N. Chira, C. Todasca, A. Nicolescu, G. Paunescu and S. Rosca, U.P.B. Sci. Bull. Series B 71, 3 (2009).

[25]. N.-A. Chira, M.-C. Todasca, A. Nicolescu, A. Rosu, M. Nicolae and S.-I. Rosca, Rev. Chim. (Bucharest) 62, 42 (2011).

[26]. M. C. Todasca, S. Zarbock-Udrea, C. Deleanu, and S. Rosca, Rev. Chim. (Bucharest) 57, 1019 (2006).

[27]. N. Ciocarlan, S. Zarbock-Udrea and C. Deleanu, Bul. Acad. St. Mold. 1, 70 (2007).

[28]. A. Nicolescu and C. Deleanu, J. Colloid Surf. Chem. 8, 53 (2008).

[29]. M. Balan, A. Nicolescu, C. Stavarache, M. Ciobanu and C. Deleanu, Rev. Roum. Chim. 58, 175 (2013).

[30]. M.-C. Todasca, N. Chira, C. Deleanu and S. Rosca, UPB Sci. Bull., Ser. B 69, 3 (2007).

[31]. M.-C. Todasca, N. Chira, M. Avramescu, A. Rubeli, C. Deleanu and S. Rosca, Rev. Chim. (Bucharest) 59, 1101 (2008).

[32]. M.-C. Todasca, L. Fotescu, N.-A. Chira, C. Deleanu and S. Rosca, Rev. Chim. (Bucharest) 62, 131 (2011).

[33]. C. Deleanu, "Nuclear Magnetic Resonance Spectroscopy Applications. Food", in "Encyclopedia of Analytical Science", $2^{\text {nd }}$ Edn, (P. J. Worsfold, A. Townshend, and C. F. Poole, Eds.), Elsevier, Oxford, 2005. Volume 6, pp. 303-315.

[34]. C. Deleanu and J. R. J. Paré, "Nuclear Magnetic Resonance Spectroscopy (NMR): Principles and Applications", in "Instrumental Methods in Food Analysis" (Eds. J. R. J. Paré and J. M. R. Bélanger), Elsevier, New York, 1997. Chapter 6, pp. 179237.

[35]. V. Kraujalyte, P. R. Venskutonis, A. Pukalskas, L. Cesoniene and R. Daubaras, Food Chem., 188, 583 (2015).

[36]. D.-J. Kwon, H.-J. Jeong, H. Moon, H.-N. Kim, J.-H. Cho, J.-E. Lee, K. S. Hong and Y.-S. Hong, Food Res. Int., 67, 175 (2015).

Received: 16 June 2015

Received in revised form: 5 July 2015 Accepted: 5 July 2015 